\title{
TNF- $\alpha$ Differentially Regulates Synaptic Plasticity in the Hippocampus and Spinal Cord by Microglia-Dependent Mechanisms after Peripheral Nerve Injury
}

\author{
다ong Liu,,${ }^{1,2,3 *}$ Li-Jun Zhou, ${ }^{1,2 *}$ 이un Wang, ${ }^{1 *}$ Dai Li, ${ }^{1}$ Wen-Jie Ren, ${ }^{1}$ ๑Jiyun Peng,,${ }^{2,6}$ Xiao Wei, ${ }^{1}$ Ting Xu, ${ }^{1}$ \\ 늘 -Jun Xin, ${ }^{1,7}$ Rui-Ping Pang, ${ }^{1}$ Yong-Yong Li, ${ }^{1}$ Zhi-Hai Qin, ${ }^{5}$ @Madhuvika Murugan, ${ }^{2,6}$ Mark P. Mattson, ${ }^{3,4}$ \\ - Long-Jun Wu, ${ }^{2,6}$ and Xian-Guo Liu ${ }^{1,7}$ \\ ${ }^{1}$ Pain Research Center and Department of Physiology, Zhongshan School of Medicine of Sun Yat-sen University, Guangzhou 510080, China, ${ }^{2}$ Department of \\ Cell Biology and Neuroscience, Rutgers University, Piscataway, New Jersey 08854, ${ }^{3}$ Laboratory of Neurosciences, National Institute on Aging Intramural \\ Research Program, Baltimore, Maryland 21224, ${ }^{4}$ Department of Neuroscience, Johns Hopkins University School of Medicine, Baltimore, Maryland 21205, \\ ${ }^{5}$ National Laboratory of Biomacromolecules, Chinese Academy of Sciences-University of Tokyo Joint Laboratory of Structural Virology and Immunology, \\ Beijing, 100101 China, ${ }^{6}$ Department of Neurology, Mayo Clinic, Rochester, Minnesota 55905, and ${ }^{7}$ Guangdong Provincial Key Laboratory of Brain Function \\ and Disease, Guangzhou, 510080 China
}

Clinical studies show that chronic pain is accompanied by memory deficits and reduction in hippocampal volume. Experimental studies show that spared nerve injury (SNI) of the sciatic nerve induces long-term potentiation (LTP) at C-fiber synapses in spinal dorsal horn, but impairs LTP in the hippocampus. The opposite changes may contribute to neuropathic pain and memory deficits, respectively. However, the cellular and molecular mechanisms underlying the functional synaptic changes are unclear. Here, we show that the dendrite lengths and spine densities are reduced significantly in hippocampal CA1 pyramidal neurons, but increased in spinal neurokinin-1-positive neurons in mice after SNI, indicating that the excitatory synaptic connectivity is reduced in hippocampus but enhanced in spinal dorsal horn in this neuropathic pain model. Mechanistically, tumor necrosis factor-alpha (TNF- $\alpha$ ) is upregulated in bilateral hippocampus and in ipsilateral spinal dorsal horn, whereas brain-derived neurotrophic factor (BDNF) is decreased in the hippocampus but increased in the ipsilateral spinal dorsal horn after SNI. Importantly, the SNI-induced opposite changes in synaptic connectivity and BDNF expression are prevented by genetic deletion of TNF receptor 1 in vivo and are mimicked by TNF- $\alpha$ in cultured slices. Furthermore, SNI activated microglia in both spinal dorsal horn and hippocampus; pharmacological inhibition or genetic ablation of microglia prevented the region-dependent synaptic changes, neuropathic pain, and memory deficits induced by SNI. The data suggest that neuropathic pain involves different structural synaptic alterations in spinal and hippocampal neurons that are mediated by overproduction of TNF- $\alpha$ and microglial activation and may underlie chronic pain and memory deficits.

Key words: memory deficit; microglia; neuropathic pain; SNI; synaptic plasticity; TNF- $\alpha$

Significance Statement

Chronic pain is often accompanied by memory deficits. Previous studies have shown that peripheral nerve injury produces both neuropathic pain and memory deficits and induces long-term potentiation (LTP) at C-fiber synapses in spinal dorsal horn (SDH) but inhibits LTP in hippocampus. The opposite changes in synaptic plasticity may contribute to chronic pain and memory deficits, respectively. However, the structural and molecular bases of these alterations of synaptic plasticity are unclear. Here, we show that the complexity of excitatory synaptic connectivity and brain-derived neurotrophic factor (BDNF) expression are enhanced in SDH but reduced in the hippocampus in neuropathic pain and the opposite changes depend on tumor necrosis factor-alpha/tumor necrosis factor receptor 1 signaling and microglial activation. The regiondependent synaptic alterations may underlie chronic neuropathic pain and memory deficits induced by peripheral nerve injury. 


\section{Introduction}

Chronic pain affects $\sim 20 \%$ of the world population and nearly $70 \%$ of chronic pain patients suffer from working memory deficits (Hart et al., 2000; Dick and Rashiq, 2007). The mechanism underlying the comorbidity of chronic pain and memory deficits is poorly understood. It has been proposed that pain-related sensory inputs may affect memory by disrupting attention, which is important for working memory formation (Eccleston, 1995; Awh et al., 2006). However, recent clinical studies show that the hippocampal volume is reduced in chronic pain patients, including those with chronic back pain, complex regional pain syndrome (Mutso et al., 2012), and knee osteoarthritis (Mao et al., 2016), suggesting that neuronal dystrophy in the hippocampus may contribute to memory deficits in chronic pain disorders. Experimental studies show that peripheral nerve injury, which induces chronic neuropathic pain (Decosterd and Woolf, 2000) and memory deficits in rodents (Ren et al., 2011), induces long-term potentiation (LTP) at C-fiber synapses in the spinal dorsal horn (Zhang et al., 2004), but impairs LTP at CA3-CA1 synapses in the hippocampus (Ren et al., 2011). The data suggest that the synaptic plasticity is reduced in hippocampus but enhanced in spinal dorsal horn in neuropathic pain condition. The regiondependent synaptic plastic changes may contribute the chronic pain and memory deficits, respectively. However, the cellular and molecular mechanisms underlying the changes are still unclear.

It has been well established that microglial activation and elevated tumor necrosis factor-alpha (TNF- $\alpha$ ) are critically involved in both hippocampus-dependent cognitive deficit (Griffin et al., 2006; Rowan et al., 2007) and neuropathic pain induced by nerve injury (Xu et al., 2006; Ji and Suter, 2007). Similar to peripheral nerve injury, microglial activation and TNF- $\alpha$ overproduction inhibit LTP in hippocampus (Pickering et al., 2005; Griffin et al., 2006), but are essential for the induction of spinal LTP at C-fiber synapses (Zhong et al., 2010; Wu et al., 2014). However, how microglial activation and overproduction of TNF- $\alpha$ can oppositely regulate synaptic plasticity in the hippocampus and spinal dorsal horn remains elusive.

Furthermore, chronic pain and memory deficits in human patients and in animals are long-lasing, which cannot be explained by the functional change in synaptic transmission. In the present work, we tested the hypothesis that the functional changes in synaptic plasticity initiated by peripheral nerve injury may transfer to structural synaptic alterations in the two regions. Indeed, we found that the structural and functional synaptic connections were enhanced in the spinal dorsal horn, but reduced in the hippocampus in 7-10 d after spared nerve injury (SNI) in the mouse. These opposite structural changes were prevented by deletion of TNFR1 and by inhibtion or ablation of microglia. The

Received July 13, 2016; revised Nov. 18, 2016; accepted Dec. 2, 2016.

Author contributions: Y. Liu, Z.L.-J., J.W., M.P.M., L.-J.W., and X.-G.L. designed research; Y. Liu, Z.L.-J., J.W., D.L., W.R., J.P., X.W., T.X., W.X., R.P., Y. Li, and M.M. performed research; Y. Liu, Z.L.-J., J.W., and Z.-H.Q. contributed unpublished reagents/analytic tools; Y. Liu, Z.L.-J., J.W., D.L., and W.R. analyzed data; Y. Liu, Z.L.-J., J.W., M.P.M., L.-J.W., and X.-G.L. wrote the paper.

This work was supported by the National Natural Science Foundation of China (Grants U1201223, 81200856, 30970957, 81371198, and 31000489), the National Institutes of Health (Grants R01NS088627 and R21DE025689), and the Intramural Research Program of the National Institute on Aging. We thank Dr. Wen-Biao Gan for providing $C X 3 C R 7^{\text {CreER/+ }}$ mice and Huai-Yu Gu for technical support.

The authors declare no competing financial interests.

*Y.L., L.-J.Z., and J.W. contributed equally to this work.

Correspondence should be addressed to either of the following: Xian-Guo Liu, Pain Research Center and Department of Physiology, Zhongshan School of Medicine of Sun Yat-sen University, Guangzhou 510080, China, E-mail: liuxg@mail.sysu.edu.cn or Long-Jun Wu, Rutgers University, Piscataway, NJ 08854. E-mail: Iwu@dls.rutgers.edu.

DOI:10.1523/JNEUROSCI.2235-16.2016

Copyright $\odot 2017$ the authors $\quad 0270-6474 / 17 / 370872-11 \$ 15.00 / 0$ region-dependent structural synaptic alterations may underlie the chronic neuropathic pain and associated cognitive disorders.

\section{Materials and Methods \\ Animals}

Adult male C57BL/6 mice and CX3CR1 $1^{\mathrm{CreER} /+}$ mice were used as WT controls. Adult male TNFR1-knock-out (TNFR1 KO, RRID:IMSR_JAX: 003242) C57BL/6 and CX3CR1-EGFP mice were purchased from the The Jackson Laboratory. $C X 3 C R 1^{\mathrm{CreER} /+}$ mice were obtained from Dr. Wen-Biao Gan at New York University. The mice were crossed with $R 26^{\mathrm{iDTR} /+}$ (purchased from The Jackson Laboratory) to obtain $C X 3 C R 1^{\mathrm{CreER} /+}: R 26^{\mathrm{iDTR} /+}$ mice. Sprague-Dawley rats $(8-10 \mathrm{~d}$ old $)$ were used for hippocampus or spinal slice cultures. The animals were housed in separated cages with access to food and water ad libitum. The room was kept at $23 \pm 1^{\circ} \mathrm{C}$ and $50-60 \%$ humidity under a 6:00-18:00 h light cycle. All experimental procedures were approved by the local animal care committee, conformed to Chinese guidelines and Rutgers University on the ethical use of animals, and all efforts were made to minimize the number of animals used and their suffering.

\section{SNI and behavioral tests}

The SNI was performed following the procedures described previously (Decosterd and Woolf, 2000). Briefly, under anesthesia with chloral hydrate $(0.4 \mathrm{~g} / \mathrm{kg}$, i.p.), the common peroneal and the tibial nerves were explored and tightly ligated with 5-0 silk and transected distal to the ligation, removing a 2-4 mm length of each nerve. Great care was taken to avoid any contact with or stretching of the intact sural nerve. The wound was closed in two layers.

Mechanical allodynia was assessed using von Frey hairs with the updown method. Briefly, the animals were placed under separate transparent Plexiglas chambers positioned on a wire mesh floor. Approximately 10-15 min were allowed for habituation. Each stimulus consisted of a 6-8 s application of a von Frey hair to the lateral surface of the foot with 5 min interval between stimuli. Quick withdrawal or licking of the paw in response to the stimulus was considered as a positive response.

Short-term memory (STM) was accessed by the novel object recognition test. The apparatus consisted of a round arena (diameter: $50 \mathrm{~cm}$ ) with white walls and floor. The box and objects were cleaned between trials to stop the buildup of olfactory cues. Animals received two sessions of $10 \mathrm{~min}$ each in the empty box to habituate them to the apparatus and test room. Twenty-four hours later, each mouse was first placed in the box and exposed to two identical objects for $10 \mathrm{~min}$ (sample phase). Next, one object was replaced by a new novel one and the mouse was placed back in the box and exposed to the familiar object and to a novel test object for a further $10 \mathrm{~min}$ (acquisition phase). The STM was tested 10 min after the "sample phase" (10 min retention). The experimenters measured the time spent exploring each object. The recognition index was calculated as the percentage ratio of time spent exploring the novel object over total exploration time during acquisition phase. All behavior tests were performed by at least two researchers who were blinded to genotype and treatment conditions of the mice.

\section{Acute slice preparation}

Under anesthesia with urethane (1.5 g/kg, i.p.) mice were killed for electrophysiological and morphological studies at 7-10 d after peripheral nerve injury. Either hippocampus or lumbar segments (L4-L6) of spinal cord were isolated. Coronal hippocampal slices $(300 \mu \mathrm{m})$ or parasagittal spinal cord slices $(500 \mu \mathrm{m})$ were cut using a vibratome (D.S.K DTK1000 ) and superfused with an ice-cold dissection solution containing the following (in mM): $125 \mathrm{NaCl}, 2.5 \mathrm{KCl}, 1 \mathrm{CaCl}_{2}, 6 \mathrm{MgCl}_{2}, 26 \mathrm{NaHCO}_{3}, 1.2$ $\mathrm{NaH}_{2} \mathrm{PO}_{4}$, and 25 D-glucose. Then, slices were incubated in recording solution containing the following (in $\mathrm{mM}$ ): $125 \mathrm{NaCl}, 2.5 \mathrm{KCl}, 2 \mathrm{CaCl}_{2}$, $1.2 \mathrm{MgCl}_{2}, 26 \mathrm{NaHCO}_{3}, 1.2 \mathrm{NaH}_{2} \mathrm{PO}_{4}$, and $25 \mathrm{D}$-glucose for $1 \mathrm{~h}$ at $34^{\circ} \mathrm{C}$ before transferring to the recording chamber. Both dissection and recording solutions were saturated with $95 \% \mathrm{O}_{2}$ and $5 \% \mathrm{CO}_{2}$. The hippocampal and spinal slices were recovered for $1 \mathrm{~h}$ at $34^{\circ} \mathrm{C}$ before recording or incubation of tetramethylrhodamine-conjugated substance $\mathrm{P}$ (TMR-SP, $20 \mathrm{nM}$ ) at room temperature. 


\section{Organotypic slice culture}

Sprague-Dawley rats (8-10 old) were killed rapidly under anesthesia with urethane $(1.5 \mathrm{~g} / \mathrm{kg}$, i.p.) and the brains or L4-L6 segments of spinal cord were dissected. Under aseptic conditions, $400 \mu \mathrm{m}$ coronal hippocampal slices or transverse spinal cord slices were cut using a vibroslice (WPI NSLM1) in cutting solution (Earle's balance salt solution, $25 \mathrm{~mm}$ HEPES) and collected in sterile culture medium containing 50\% MEM, $25 \%$ heat inactivated horse serum, 25\% EBSS, $6.5 \mathrm{mg} / \mathrm{ml} \mathrm{D-glucose,} 50$ $\mathrm{U} / \mathrm{ml}$ penicillin, and $50 \mu \mathrm{g} / \mathrm{ml}$ streptomycin, $\mathrm{pH}$ 7.3. The organotypic slices were carefully placed into a $0.4 \mu \mathrm{m}$ membrane insert (Millipore PICM03050) within a 6-well plate at $37^{\circ} \mathrm{C}$ and $5 \% \mathrm{CO}_{2}$ with $1 \mathrm{ml}$ of culture medium in each well. Slices were incubated for at least $6 \mathrm{~d}$ before experiments and the medium was changed twice a week. For electrophysiological recording, culture slices were incubated in recording solution containing the following (in mM): $125 \mathrm{NaCl}, 2.5 \mathrm{KCl}, 2 \mathrm{CaCl}_{2}, 1.2 \mathrm{MgCl}_{2}$, $26 \mathrm{NaHCO}_{3}, 1.2 \mathrm{NaH}_{2} \mathrm{PO}_{4}$, and $25 \mathrm{D}$-glucose for $1 \mathrm{~h}$ at $34^{\circ} \mathrm{C}$ before transfer to the recording chamber.

\section{Conditional ablation of microglia}

Microglia were killed selectively using a method described previously in which mice genetically engineered to express the diphtheria toxin receptor only in microglia (CXCR1 ${ }^{\mathrm{CreER} /+}$ mice) were treated with diphtheria toxin (Parkhurst et al., 2013; Peng et al., 2016). Briefly, CX3CR1 CreER/+ (control) mice or CX3CR1 ${ }^{\mathrm{CreER} /+}: \mathrm{R}^{2} 6^{\mathrm{iDTR} /+}(\mathrm{M}-\mathrm{Abl})$ mice (>6 weeks old) were given both tamoxifen (TM) and diphtheria toxin (DT). TM (Sigma-Aldrich T5648, $150 \mathrm{mg} / \mathrm{kg}, 20 \mathrm{mg} / \mathrm{ml}$ in corn oil with ultrasound) was injected intraperitoneally every other day from $10 \mathrm{~d}$ before surgery. DT (Sigma-Aldrich C8267, $50 \mu \mathrm{g} / \mathrm{kg}, 2.5 \mu \mathrm{g} / \mathrm{ml}$ in PBS) was given for twice at the day before and after surgery ( $4 \mathrm{~d}$ after the last TM treatment). To confirm the effectiveness of general microglial ablation in the CNS, the hippocampus and spinal cord were harvested on the third day after surgery for immunostaining of microglia.

\section{Electrophysiology}

Whole-cell recordings were performed at room temperature using an EPC-9 amplifier with Pulse version 8.65 software (HEKA). For visualizing recorded neurons under a microscope (Eclipse FN1; Nikon), infrared DIC optics (IR1000, DAGE-MTI) was used for recording in hippocampal slices. TMR-SP-positive neurons in spinal cord slices were identified under epifluorescence using a CCD camera. The EPSCs in hippocampal CA1 pyramidal neurons were recorded after electrical stimulation of Schaffer collateral-commissural pathway at $0.066 \mathrm{~Hz}$ with a bipolar tungsten-stimulating electrode. The EPSCs in spinal TMR-SP-positive neurons were evoked by stimulation of the dorsal root entry zone at 0.066 $\mathrm{Hz}$ at intensities sufficient to activate C-fibers $(0.5 \mathrm{~ms}, 200-500 \mu \mathrm{A})$; only the EPSCs evoked by the high intensities were used for further analysis (Nakatsuka et al., 2000). The extracellular solution contained picrotoxin (100 $\mu \mathrm{M}$, Sigma-Aldrich) to block fast GABAergic inhibition. The recording pipettes ( $3-5 \mathrm{M} \Omega$ ) were filled with solution containing the following (in mM): 130 Cs-gluconate, $4 \mathrm{NaCl}, 0.5 \mathrm{MgCl}_{2}, 5$ EGTA, 10 HEPES, $5 \mathrm{MgATP}, 0.5 \mathrm{Na}_{3} \mathrm{GTP}, 5 \mathrm{QX}-314$ and 1.3 biocytin, $\mathrm{pH} 7.3$ and osmolality 290-295. The AMPAR- and NMDAR-mediated components were distinguished by their differential activation and inactivation kinetics. EPSCs were recorded at different membrane potentials from -70 to $+50 \mathrm{mV}$ ( $10 \mathrm{mV}$ per step). The NMDA/AMPA current ratio is defined as the amplitude of the NMDAR component $80 \mathrm{~ms}$ after stimulation at $+50 \mathrm{mV}$ divided by the peak of the AMPAR component at $-70 \mathrm{mV}$. Miniature EPSCs (mEPSCs) were recorded at $-70 \mathrm{mV}$ in the presence of picrotoxin $(100 \mu \mathrm{M})$ and tetrodotoxin $(0.5 \mu \mathrm{M})$ in the same recording solution and using same intracellular solution above. mEPSCs were analyzed using pClamp 9 (Molecular Devices). All the detected events were reexamined and accepted or rejected on the basis of visual examination. Cells were recorded from for $\sim 5$ min to obtain at least 100 events per cell. Data obtained from the indicated number $(n)$ of cells were expressed as the mean \pm SEM and analyzed using Student's $t$ test.

\section{Visualization of neurons and morphological analysis}

To visualize recorded neurons, the intracellular marker biocytin $(1.3 \mathrm{~mm})$ was dissolved in the intracellular solution/pipette solution de- scribed above. After least 15 min of whole-cell patch recording, the slices were fixed with $4 \%$ paraformaldehyde in PBS and then processed using Alexa Fluor 594 streptavidin (Life Technologies) for visualization. Neuronal dendrites and dendritic spines were imaged by confocal microscopy (Zeiss LSM 710) through $20 \times$ and $63 \times$ objectives, respectively. The images were digitally reconstructed and the sum lengths and number of branch points of dendrite were automatically analyzed with Imaris scientific software (Bitplane, RRID:SCR_007370). This study focused on the hippocampal CA1 pyramidal neurons and on the neurokinin-1positive neurons (NK1-PNs) in spinal lamina I, which is critical for the development of neuropathic pain (Mantyh et al., 1997). The hippocampal CA1 pyramidal neurons were identified by their location within the CA1 cell body layer and by their classic pyramidal shaped soma, apical dendrites, and basal dendrites. Spinal NK1-PNs were identified by incubation of spinal cord slices with tetramethylrhodamine-conjugated substance $\mathrm{P}$ with red fluorescence that binds to the NK-1 receptor and therefore labels NK1-PNs (Pagliardini et al., 2005). It has been shown that $\sim 80 \%$ of lamina I neurons express NK-1 receptor and virtually all (99\%) of the NK-1 receptor-expressing neurons with soma areas $>200 \mu \mathrm{m}^{2}$ are projection neurons (Al Ghamdi et al., 2009). Accordingly, only the NK1-PNs with soma areas $>200 \mu \mathrm{m}^{2}$ were recorded from in the present study. The Sholl analysis of neuronal dendrites was also performed with Imaris to provide a quantitative description of the dendritic tree by evaluating the number of dendrites that crossed through virtual concentric circles at equal distances centered in the soma of a neuron. The number of spines was manually counted in Imaris, which can show clear spine and $3 \mathrm{D}$ actual length according to a previous work. For each hippocampal CA1 pyramidal neuron, the spines in the principal apical dendrite were counted in a 50-100 $\mu \mathrm{m}$ segment, which was at least $50 \mu \mathrm{m}$ away from the center of the soma, and a $30 \mu \mathrm{m}$ segment of secondary apical dendrite. The spines in basal dendrite were counted in two $15 \mu \mathrm{m}$ segments, which were at least $20 \mu \mathrm{m}$ from the soma. For each NK1-PN in lamina I in spinal cord, spine counting was performed on four 20-50 $\mu \mathrm{m}$ segments of the dendrite (the proximal end of this segment was never closer than $50 \mu \mathrm{m}$ from the center of the soma). Spines were counted only if they had both a punctuate head and visible neck. A subset of neurons was counted by two different investigators to ensure consistency of counting. No significant differences were found when the same segment was counted by different investigators.

\section{Western blot}

Frozen tissues of hippocampus and spinal dorsal horn were homogenized and equal amounts of proteins were resolved on polyacrylamide gel and then transferred to PVDF membranes (BD Biosciences). Membranes were blocked and then probed with primary antibodies: mouse antiTNF- $\alpha$ (AF-410; R\&D Systems), rabbit anti-BDNF (AB1534; Millipore), and mouse anti- $\beta$-actin (\#3700, Cell Signaling Technology) overnight at $4^{\circ} \mathrm{C}$. Membranes were then incubated with an HRP-conjugated secondary antibody at room temperature. Protein bands were detected by ECL detection reagent (RPN2232; GE Healthcare) and captured on autoradiography film (Kodak). Integrated optical density was determined using Image-Pro Plus software version 6.0 (Media Cybernetics). Standard curves were constructed to establish that we operated within the linear range of the detection method.

\section{Immunohistochemistry}

Mice were deeply anesthetized with isoflurane $\left(5 \%\right.$ in $\left.\mathrm{O}_{2}\right)$ and perfused transcardially with $20 \mathrm{ml}$ of PBS followed by $20 \mathrm{ml}$ of cold $4 \%$ paraformaldehyde (PFA) in PBS containing 1.5\% picric acid. The brain and spinal cord were removed and postfixed with the same $4 \%$ PFA for overnight (brain) or $4-6 \mathrm{~h}$ (spinal cord) at $4^{\circ} \mathrm{C}$. The samples were then transferred to $30 \% \mathrm{su}-$ crose in PBS overnight. Sample sections (14 $\mu \mathrm{m}$ in thickness) were prepared on gelatin-coated glass slide with a cryostat (Leica). The sections were blocked with $5 \%$ goat serum and $0.3 \%$ Triton X-100 (Sigma-Aldrich) in TBS buffer for $60 \mathrm{~min}$ and then incubated overnight at $4^{\circ} \mathrm{C}$ with primary antibody for rabbit-anti-Ibal (1:1000; Wako). The sections were then incubated for $60 \mathrm{~min}$ at room temperature with secondary antibodies (goat anti-rabbit Alexa Fluor 594; Life Technologies). The stained sections were examined 

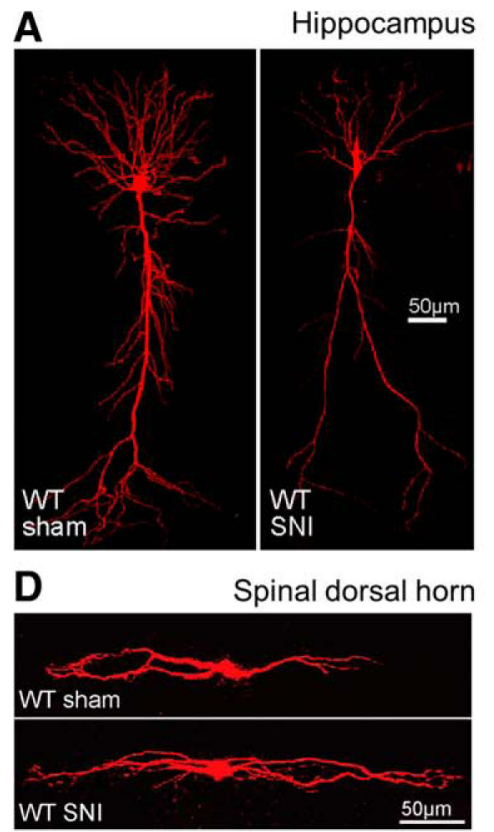
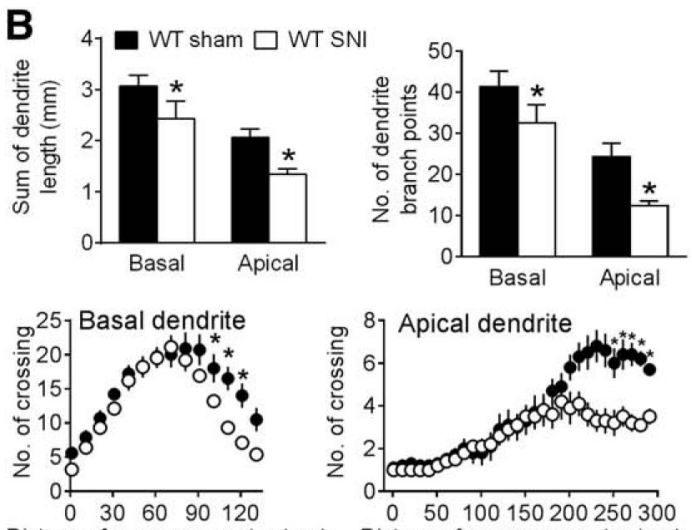

Distance from soma center $(\mu \mathrm{m})$

\section{E}

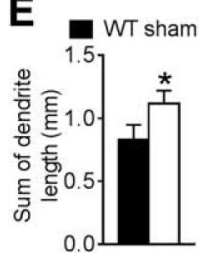

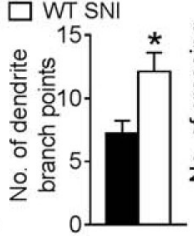

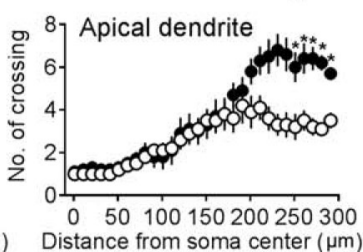

Distance from soma center ( $\mu \mathrm{m})$

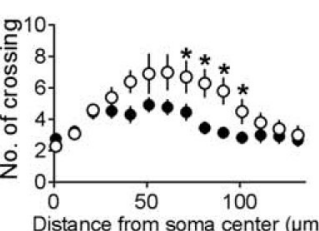

C
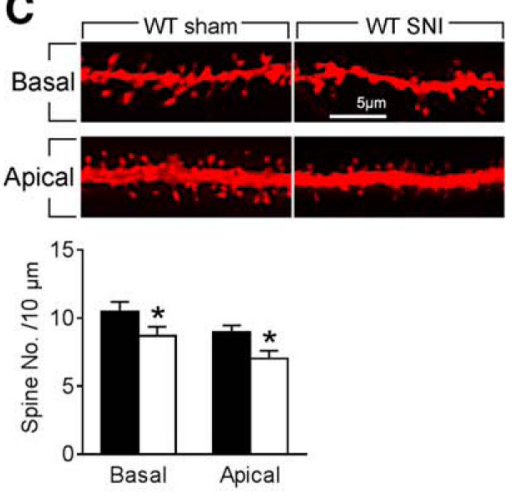

$\mathbf{F}$
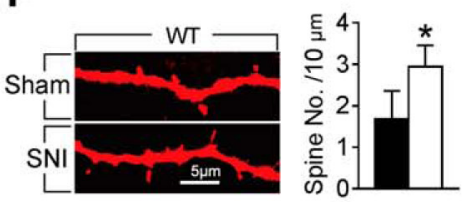

Figure 1. Synaptic connectivity is decreased in hippocampus, but increased in spinal dorsal horn after SNI. $\boldsymbol{A}, \boldsymbol{B}$, Representative images of biocytin-labeled CA1 pyramidal neurons and summary data of dendritic length ( $n=12$, basal, $p=0.024$; apical, $p=0.002$ ), branch number ( $n=12$; basal, $p=0.024$, apical, $p=0.002)$, and Sholl analysis in WT from the sham and SNI groups ( $n=12$, $p=0.012$ ). C, Representative images and summary data of dendritic spine densities of CA1 neurons in the indicated groups ( $n=12$, basal, $p=0.023$; apical, $p=0.021)$. Twelve neurons from six mice per group were analyzed. $\boldsymbol{D}, \boldsymbol{E}$, Representative images and the summary data of dendritic length $(n=14, p=0.024)$, branch number $(n=14, p=0.016)$, and Sholl analysis of spinal NK1-PNs in sham and SNI groups of WT mice $(n=14, p=0.014)$ are shown. $\boldsymbol{F}$, Representative images and summary data of dendritic spine densities of spinal NK1-PNs in the indicated groups ( $n=14, p=$ 0.023 ) are shown. Fourteen neurons from six mice per group were analyzed. Values are the mean $\pm S E M .{ }^{*} p<0.05$ versus sham groups. Data for all bar graphs were analyzed using Student's $t$ test. Data for graphs in which Sholl analyses is plotted were analyzed using repeated-measures two-way ANOVA.

with a Leica DFC350 FX fluorescence microscope and images were captured with a CCD spot camera.

The number of $\mathrm{GFP}^{+}$cells or the percentage of $\mathrm{GFP}^{+}$area was countered or detected using ImageJ software. To quantify immunoreactivity profiles in the spinal cord and hippocampus, three to five L4-L5 spinal cord or hippocampal sections per mouse from three mice were selected randomly for each group.

\section{Quantification of microglia}

All fluorescence images were captured on an EVOS FL (Thermo Fisher) imaging station with a $20 \times$ objective lens and the qualitative and quantitative analyses of images were performed in a blinded fashion. $\mathrm{GFP}^{+}$ cells or the percentage of $\mathrm{GFP}^{+}$area within hippocampus CA1 or the medial two-thirds of the spinal dorsal horn on the ipsilateral side after SNI were counted/measured using ImageJ software. When $\mathrm{GFP}^{+}$cell number counting, image contrast was adjusted to eliminate background fluorescence and the same cutoff level was used for all images. For GFP ${ }^{+}$ area, the images were converted digitally into a grayscale image before commencing the analysis. Only the $\mathrm{GFP}^{+}$cell bodies with DAPI-stained nuclei were included in the analysis. To quantify immunoreactivity profiles, three to five L4-L5 spinal cord or hippocampal sections per mouse from three mice were selected randomly for each group.

\section{Flow cytometry}

At $7 \mathrm{~d}$ after SNI, the bilateral hippocampus and L4-L5 spinal dorsal horn were harvested from CX3CR1-EGFP mice and digested using Neural Tissue Dissociation Kits (Miltenyi Biotec) and proteolytic enzymes to obtain single-cell suspensions. Then, the microglia were isolated from the cell suspensions by discontinuous density gradient centrifugation using 30\% isotonic Percoll (GE Healthcare) and stained with APC antimouse/human CD11b Antibody (101212; BioLegend) and its isotype control for $45 \mathrm{~min}$. The percentage of CX3CR1-EGFP, CD11b+ microglia were compared between the sham and SNI groups $(n=3-4$ mice (group). Data acquisition was performed on a flow cytometer
(FACSCalibur; BD Biosciences) and analyzed with FlowJo (TreeStar) software blinded to treatment group.

\section{Statistics}

The data for the Sholl analysis of dendrite distribution with repeatedmeasures two-way ANOVA and post hoc tests were used for detailed statistical analysis as appropriate. The behavioral data were analyzed by one-way repeated-measures ANOVA when compared within the group and by two-way ANOVA when compared between groups. The results of others were analyzed with Student's $t$ test. All data are expressed as means \pm SEM. Statistical tests were performed with SPSS version 16.0 software. $p<0.05$ was considered significant.

\section{Results}

SNI regulates structural synaptic connectivity oppositely in the hippocampus and in spinal dorsal horn

This study focused on the NK1-PNs in spinal lamina I, which are critical for the development of neuropathic pain (Mantyh et al., 1997), and on hippocampal CA1 pyramidal neurons. There are three types of lamina I neurons based on cell morphology: fusiform, multipolar, and pyramidal. In the present study, the lamina I NK1-PNs in each group used for morphological analysis included $53 \pm 0.053 \%$ fusiform, $42 \pm 0.068 \%$ multipolar, and $5 \pm$ $0.037 \%$ pyramidal cells. This is consistent with previous studies in rats (Yu et al., 2005) and monkeys (Yu et al., 1999) showing that NK-1 receptors are expressed mainly in fusiform and multipolar neurons, but less in pyramidal lamina I neurons.

Compared with sham-operated mice, the total dendrite length, number of dendrite branch points, and spine densities in the basal and apical dendrites of CA1 pyramidal neurons were reduced significantly (Fig. $1 A-C$ ), whereas all of these measures of dendritic complexity were enhanced in spinal NK1-PNs (Fig. 

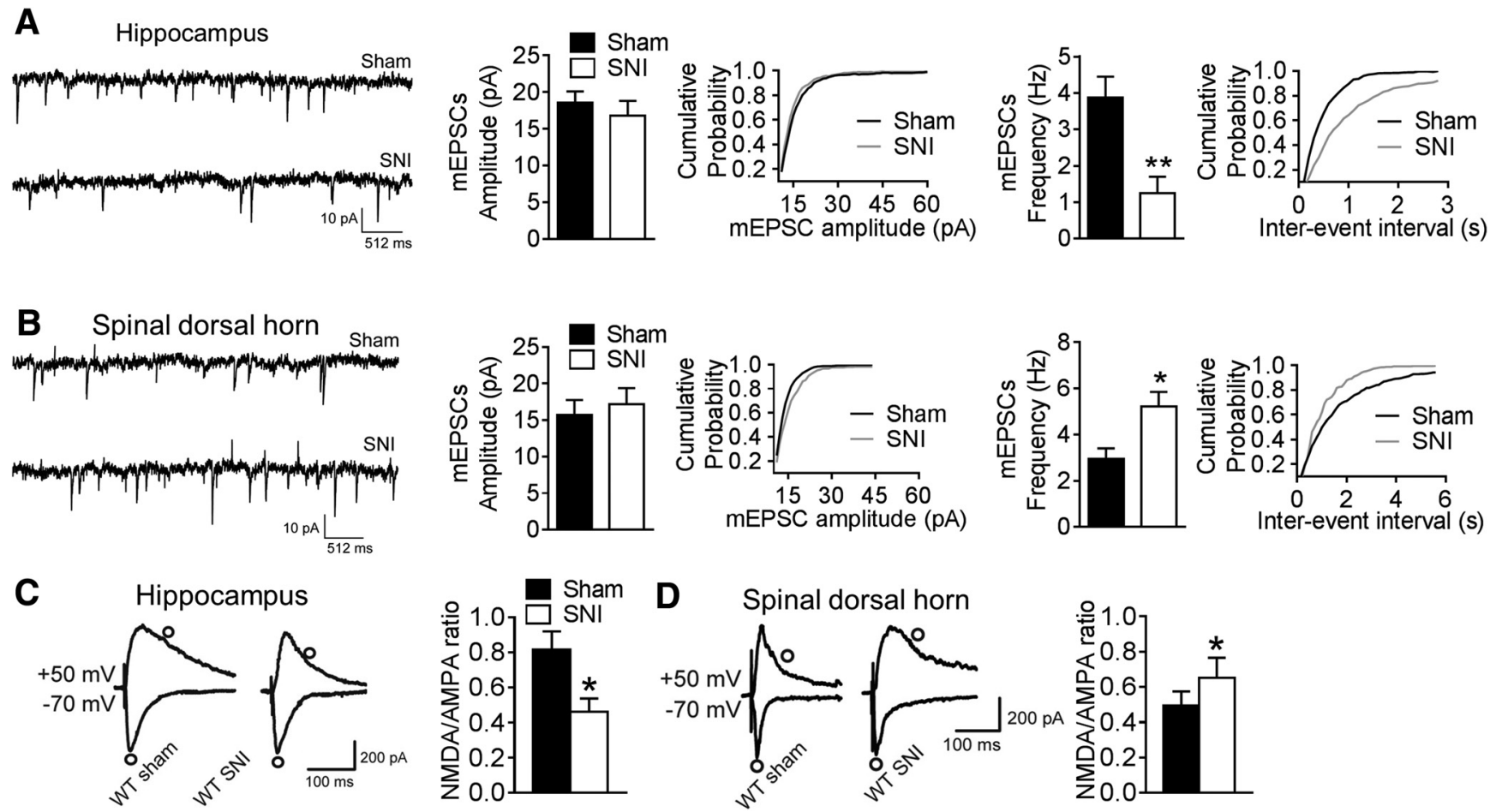

Figure 2. SNI induces differential changes in synaptic transmission. $A$, Representative mEPSCs of CA1 pyramidal neurons, their amplitude, cumulative probability, and frequency in WT mice from the sham and SNI groups ( $n=12$, amplitude, $p=0.659$; frequency, $p=0.008 ; 12$ neurons from 6 mice per group). $\boldsymbol{B}$, Representative mEPSCs of spinal NK1-PNs, their amplitude, cumulative probability, and frequency in WT mice from the sham and SNI groups ( $n=10$, amplitude, $p=0.819$; frequency, $p=0.012 ; 10$ neurons from 5 mice per group). $C$, NMDA/AMPA current ratios at CA3-CA1 synapses in the indicated groups ( $n=15, p=0.021 ; 15$ neurons from 6 mice per group). Evoked AMPA receptor EPSC (bottom traces) and evoked NMDA receptor EPSC (top traces) were recorded at membrane potentials of -70 and $+50 \mathrm{mV}$, respectively. Circles indicate the time at which the amplitudes of AMPA or NMDA receptor currents were measured. $D$, NMDA/AMPA current ratio in spinal NK1-PNs in the different groups ( $n=16, p=0.022 ; 16$ neurons from 6 mice per group). Values are the mean \pm SEM. ${ }^{*} p<0.05,{ }^{* *} p<0.01$ versus sham groups. Data for all bar graphs were analyzed using Student's $t$ test.

$1 D-F$ ) 7-10 d after SNI in mice. Sholl analysis revealed that reduced dendritic branching (number of crossings) in basal dendrites of CA1 neurons was evident between 110 and $140 \mu \mathrm{m}$ from the soma, in apical dendrites between 230 and $300 \mu \mathrm{m}$ (Fig. 1B), and in spinal NK1-positive PNs between 70 and $90 \mu \mathrm{m}$ (Fig. 1E) in SNI mice compared with sham mice. The results indicate that SNI affects structural synaptic connectivity in a regiondependent manner. Because most excitatory synapses are located in spines (Sorra and Harris, 2000), these results demonstrate that the number of excitatory synapses is reduced in hippocampal pyramidal neurons, but enhanced in spinal NK1-PNs under neuropathic pain conditions.

\section{Synaptic efficacy is decreased in the hippocampus but} increased in spinal dorsal horn after SNI

Having shown that SNI increases dendritic complexity and spine density in spinal NK1-PNs, but decreases dendritic complexity and spine density in hippocampal CA1 neurons, we next tested whether the structural changes were associated with changes in synaptic connectivity in the 2 regions $7-10 \mathrm{~d}$ after SNI. Indeed, we found that, compared with sham mice, the frequency of mEPSCs was lower in CAl pyramidal neurons but higher in spinal NK1-PNs in SNI mice (Fig. 2A,B). The amplitudes of mEPSCs in both CA1 pyramidal neurons and spinal NK1-PNs were not different between the SNI and sham groups (Fig. $2 A, B$ ). The results indicate that the strength of synaptic connectivity is decreased in hippocampal neurons but increased in spinal NK1-PNs, which may result from opposite changes in numbers of excitatory synapses in the two regions in response to SNI.
To investigate whether SNI also affects the synaptic plasticity in the two regions differentially, we next tested the effect of SNI on the NMDA/AMPA ratio, which reflects synaptic plasticity (Lau and Zukin, 2007), in hippocampal and spinal slices with whole-cell patch-clamp recordings. We found that the NMDA/ AMPA ratio was significantly lower at CA3-CA1 synapses (Fig. $2 C$ ), but was higher at synapses between primary afferents and spinal NK1-PNs (Fig. 2D) in SNI mice compared with sham mice. These suggest that the synaptic plasticity is decreased in hippocampus but increased in dorsal horn after peripheral nerve injury, which is in consistence with previous studies showing that SNI impairs LTP in hippocampus (Ren et al., 2011) but facilities LTP in spinal dorsal horn (Liu et al., 2007).

The morphological and electrophysiological data demonstrated that SNI induced opposite changes in structural synaptic connectivity, in excitatory synaptic transmission, and in synaptic plasticity in hippocampus and in spinal dorsal horn. The following experiments were focused on the mechanisms by which SNI produces the structural synaptic changes and behavioral abnormalities.

\section{Effects of SNI on the expression of TNF- $\alpha$ and BDNF in hippocampus and in spinal dorsal horn}

Previous studies showed that elevation of TNF- $\alpha$ is involved in both chronic neuropathic pain (Xu et al., 2006) and memory deficits (Ren et al., 2011) after peripheral nerve injury. BDNF, which is critical for synapse formation, plays important roles in hippocampus-dependent memory (Park and Poo, 2013) and chronic pain (Groth and Aanonsen, 2002; Zhou et al., 
A

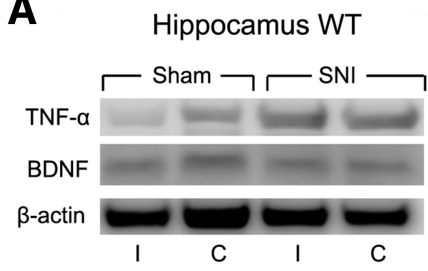

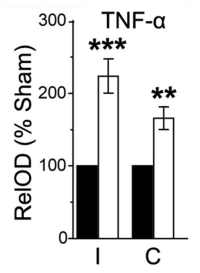

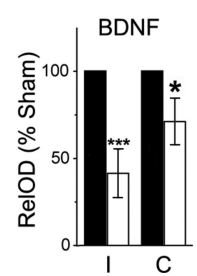

B

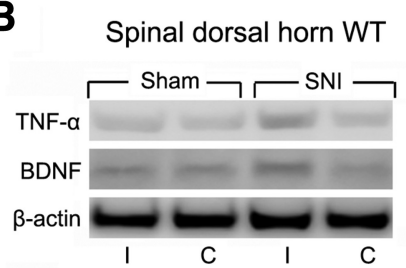

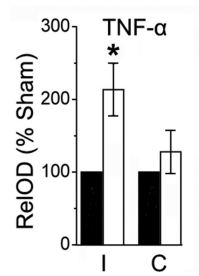

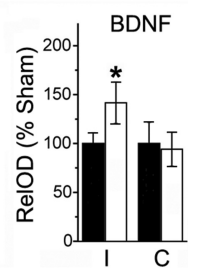

Figure 3. Effects of SNI on TNF- $\alpha$ and BDNF expression in hippocampus and spinal dorsal horn. $A$, Western blots showing the levels of TNF- $\alpha$ (26 kDa) and BDNF (18 kDa) in contralateral (C) and ipsilateral (I) hippocampus of WT mice in sham and SNI groups: $n=5$, TNF- $\alpha, p<0.001$ (I), $p=0.009$ (C); BDNF, $p<0.001$ (I), $p=0.021$ (C). B, Levels of TNF- $\alpha$ and BDNF in contralateral and ipsilateral spinal dorsal horn in the indicated groups: $n=5$, TNF- $\alpha, p=0.014(\mathrm{I}), p=0.662$ (C); BDNF, $p=0.032$ (I), $p=0.737$ (C). RelOD, Relative optical density. Values are the mean \pm SEM. ${ }^{*} p<0.05,{ }^{* *} p<0.01,{ }^{* * *} p<0.001$ versus sham groups. Data for all bar graphs were analyzed using Student's $t$ test.

A

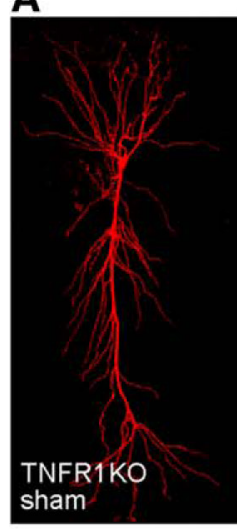

D
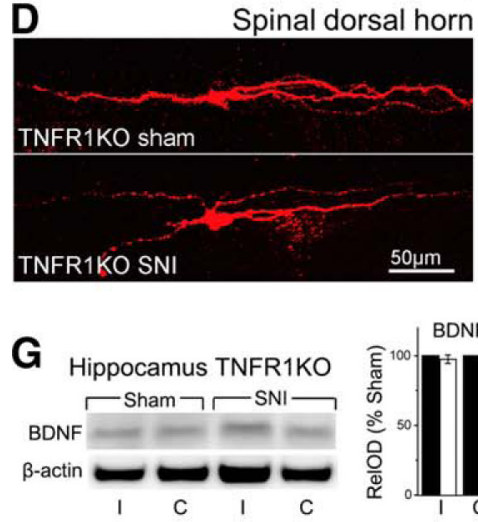

Hippocampus

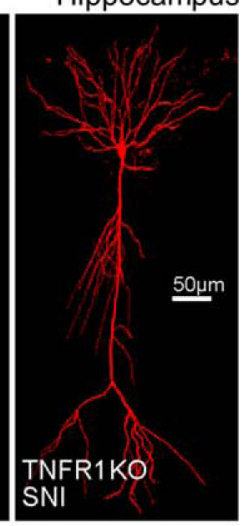

$\underline{50 \mu m}$

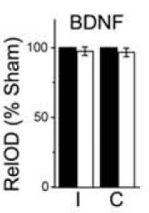

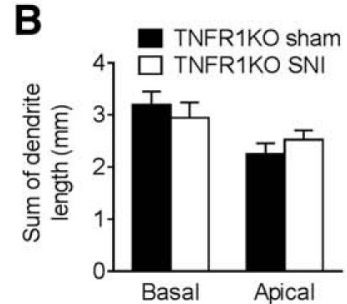

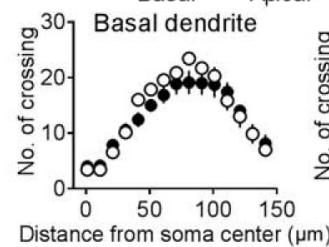

Distance from soma center $(\mu \mathrm{m})$
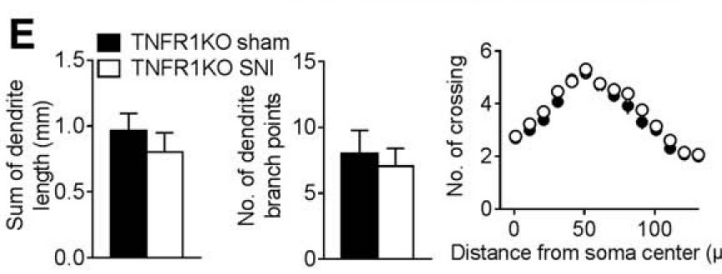

Distance from soma center $(\mu \mathrm{m})$

\section{C}
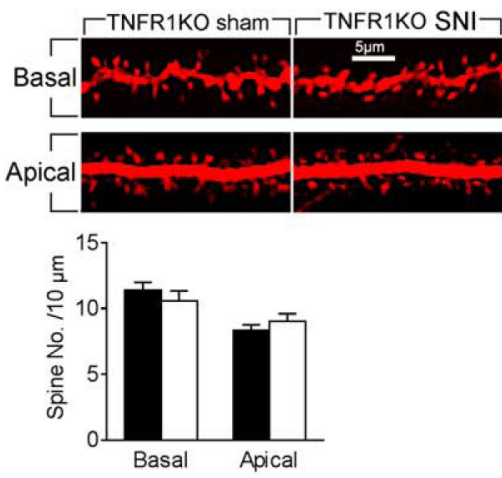

\section{$\mathbf{F}$}
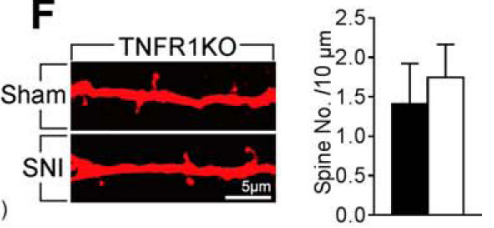

Figure 4. Effects of SNI on synaptic connectivity and BDNF expression are prevented by genetic deletion of TNFR 1. $A$, $B$, Representative images of biocytin-labeled CA1 pyramidal neurons $(\boldsymbol{A})$ and their indicated dendritic length $(\boldsymbol{B})(n=12$, basal, $p=0.361$; apical, $p=0.335)$, branch number $(n=12$, basal, $p=0.395 ;$ apical, $p=0.605)$, and Sholl analysis $(n=$ $12, p=0.231)$ in TNFR1 K0 mice from the sham and SNI groups. C, Representative images and summary data of dendritic spine densities of CA1 neurons in the indicated groups $(n=$ 12 , basal, $p=0.406$; apical, $p=0.369$ ). Twelve neurons from six mice per group were used for the morphological analysis. $\boldsymbol{D}, \boldsymbol{E}$, Representative images and the summary data of dendritic length $(n=14, p=0.234)$, branch number $(n=14, p=0.394)$, and Sholl analysis of spinal NK1-PNs in sham and SNI groups of TNFR1 K0 mice $(n=14, p=0.320) . \boldsymbol{F}$, Representative images and summary data of dendritic spine densities of spinal NK1-PNs in the indicated groups ( $n=14, p=0.234$ ). Fourteen neurons from six mice per group were analyzed. $\mathbf{G}$, Western blots showing the level of BDNF in contralateral (C) and ipsilateral (I) hippocampus or spinal dorsal horn of TNFR1 K0 mice in sham and SNI groups: hippocampus, $n=5, p=$ $0.422(\mathrm{C}), p=0.485(\mathrm{I})$; spinal dorsal horn, $n=5, p=0.298)(\mathrm{C}), p=0.372$ (I). Data for all bar graphs were analyzed using Student's $t$ test. Data for graphs in which Sholl analyses is plotted were analyzed using repeated-measures two-way ANOVA.

2010). To explore the molecules that may contribute to the opposite changes in the dendritic structural and synaptic connectivity changes occurring in SNI, we measured TNF- $\alpha$ and BDNF protein levels in the hippocampus and spinal dorsal horn 7-10 d after SNI. TNF- $\alpha$ levels increased in bilateral hippocampus and in ipsilateral spinal dorsal horn, whereas BDNF protein decreased in both hippocampi but increased in the ipsilateral spinal dorsal horn compared with sham groups (Fig. $3 A, B$ ). These results suggest that overproduction of TNF- $\alpha$ may regulate BDNF expression differentially in hippocampus and spinal dorsal horn.
SNI-induced changes in synaptic connectivity are mediated by TNF- $\alpha / T N F R 1$ signaling

To determine the role of TNF- $\alpha$ for the changes in structural synaptic change and BDNF expression induced by SNI, we performed experiments with TNFR1 KO mice. There was no difference in the total dendrite lengths, number of dendrite branch points, and spine densities in CA1 pyramidal neurons (Fig. $4 A-C$ ) and in spinal NK1-PNs (Fig. $4 D-F$ ) in SNI compared with sham groups of TNFR1 KO mice. Interestingly, just like the changes in synaptic connectivity described above, the opposite regulation of BDNF expression by SNI was also prevented by genetic deletion of TNFR1 
A

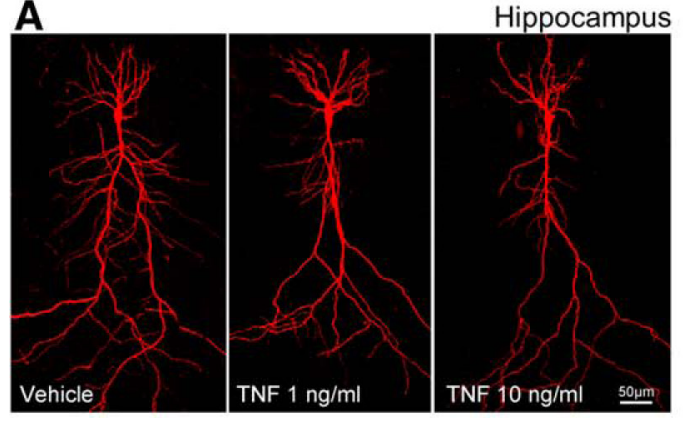

D
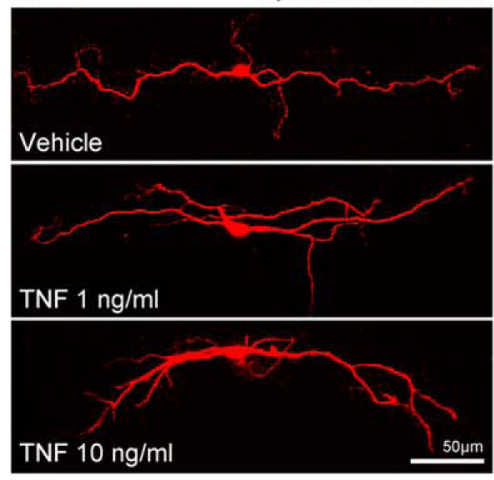

B

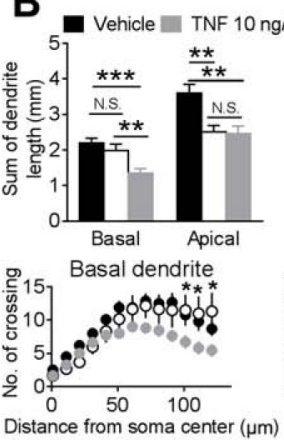

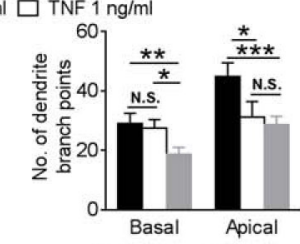

Apical dendrite

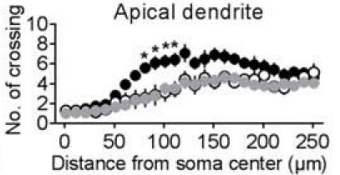

C
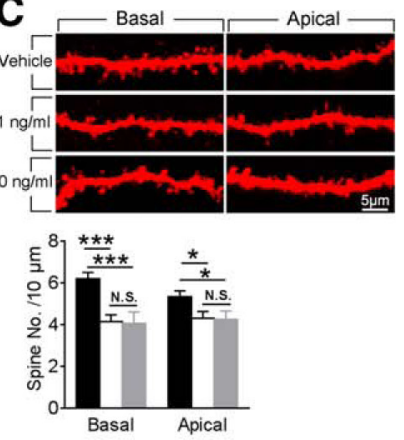

E

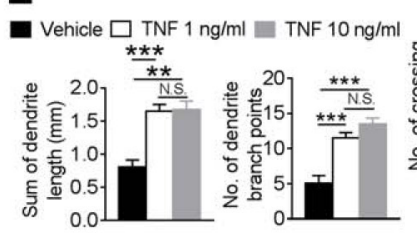

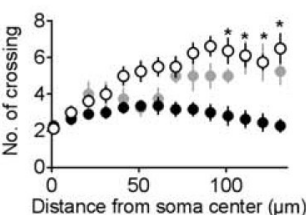
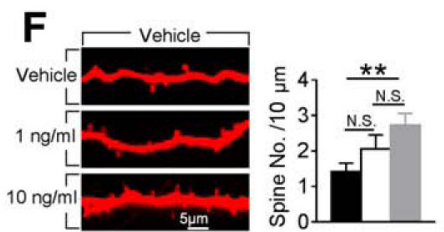

G

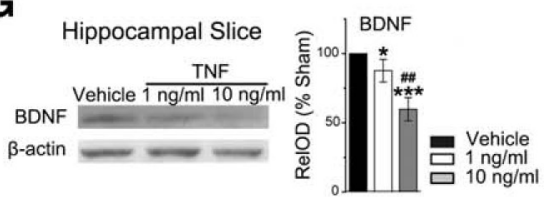

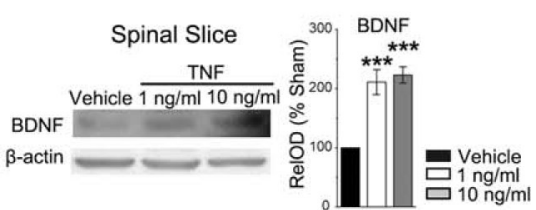

Figure 5. TNF- $\alpha$ modulates synaptic connectivity and BDNF expression differentially in cultured slices. $A, B$, Representative images of biocytin-labeled CA1 pyramidal neurons and their indicated dendritic length $(n=12$, basal, vehicle vs $1 \mathrm{ng}, p=0.368$, vehicle vs $10 \mathrm{ng}, p<0.001,1 \mathrm{ng}$ vs $10 \mathrm{ng}, p=0.007$; apical, vehicle vs $1 \mathrm{ng}, p=0.005$, vehicle vs $10 \mathrm{ng}, p=0.001,1 \mathrm{ng}$ vs $10 \mathrm{ng}, p=$ 0.898 ), branch number ( $n=12$, basal, vehicle vs $1 \mathrm{ng}, p=0.692$, vehicle vs $10 \mathrm{ng}, p=0.003,1 \mathrm{ng}$ vs $10 \mathrm{ng}, p=0.013$; apical, vehicle vs $1 \mathrm{ng}, p=0.044$, vehicle vs $10 \mathrm{ng}, p<0.001,1 \mathrm{ng}$ vs 10 $\mathrm{ng}, p=0.208)$, and Sholl analysis $(n=14, p=0.012)$ in the slices treated with vehicle and rrTNF- $\alpha$ (TNF) at the indicated concentrations. $C$, Representative images and summary data showing dendritic spine densities in CA1 pyramidal neurons in vehicle- and TNF-treated slices ( $n=12$, basal, vehicle vs $1 \mathrm{ng}, p<0.001$, vehicle vs $10 \mathrm{ng}, p<0.001,1 \mathrm{ng}$ vs $10 \mathrm{ng}, p=0.895 ;$ apical, vehicle vs $1 \mathrm{ng}, p=0.026$, vehicle vs $10 \mathrm{ng}, p=0.02,1 \mathrm{ng}$ vs $10 \mathrm{ng}, p=0.914$ ). Twelve neurons in 12 slices from six rats per group were analyzed. $\boldsymbol{D}, \boldsymbol{E}$, Representative images and dendritic measurements of spinal NK1-PNs in vehicle- and TNF-treated slices ( $n=12$, dendritic length, vehicle vs $1 \mathrm{ng}, p<0.001$, vehicle vs $10 \mathrm{ng}, p=0.001,1 \mathrm{ng}$ vs $10 \mathrm{ng}, p=0.875$; branch number, vehicle vs $1 \mathrm{ng}, p<$ 0.001 , vehicle vs $10 \mathrm{ng}, p<0.001$, $1 \mathrm{ng}$ vs $10 \mathrm{ng}, p=0.126$; Sholl analysis, $n=12, p=0.022)$. $\boldsymbol{F}$, Dendritic spines of NK1-PNs were increased by TNF $(n=12$, vehicle vs $1 \mathrm{ng}, p=0.211$, vehicle vs $10 \mathrm{ng}, p=0.004,1 \mathrm{ng}$ vs $10 \mathrm{ng}, p=0.218$ ). Twelve neurons in 12 slices from six rats per group were analyzed. G, Western blots showing BDNF levels in the hippocampal and spinal slice cultures in the indicated groups ( $n=5$, vehicle vs $1 \mathrm{ng}, p=0.035$, vehicle vs $10 \mathrm{ng}, p<0.001,1 \mathrm{ng}$ vs $10 \mathrm{ng}, p=0.022$ ). Thirty to 35 slices from five rats per group were analyzed. Values are the mean \pm SEM. ${ }^{*} p<0.05,{ }^{* *} p<0.01,{ }^{* * *} p<0.001$ versus vehicle; $\# p<0.05$, \#\#p $<0.01$ versus $1 \mathrm{ng} / \mathrm{ml}$. Data for all bar graphs were analyzed using one-way ANOVA. Data for graphs in which Sholl analyses is plotted were analyzed using repeated-measures two-way ANOVA.

(Fig. 3G). Therefore, TNFR1 may be necessary for the morphological synaptic changes induced by SNI.

To test whether TNF- $\alpha$ is sufficient to induce the differential changes in structural synaptic connectivity and BDNF expression in hippocampus and in spinal dorsal horn, we cultured rat hippocampal and spinal cord slices with recombinant rat TNF- $\alpha$ (rrTNF- $\alpha$ ) at different concentrations (Fig. 5). A rrTNF- $\alpha$ concentration of $10 \mathrm{ng} / \mathrm{ml}$ reduced the basal dendrite lengths and the number of basal dendrite branch points in CA1 pyramidal neurons, whereas the apical dendritic length, apical branch number, and both basal and apical spine densities were reduced significantly with 1 and $10 \mathrm{ng} / \mathrm{ml}$ rrTNF- $\alpha$ (Fig. $5 A-C$ ). In spinal NK1-PNs, rrTNF- $\alpha$ at concentrations of 1 and $10 \mathrm{ng} / \mathrm{ml}$ increased total dendrite lengths and the number of dendrite branch points significantly and dendritic spine density was increased significantly with $10 \mathrm{ng} / \mathrm{ml} \operatorname{rrTNF}-\alpha$ (Fig. $5 D-F$ ). Furthermore, $\operatorname{rrTNF}-\alpha$ at concentrations of 1 and $10 \mathrm{ng} / \mathrm{ml}$ downregulated BDNF in hippocampal slices significantly, but upregulated BDNF in spinal slices (Fig. $5 G$ ). Therefore, TNF- $\alpha$ /TNFR1 signaling may be sufficient to induce CNS-region-dependent changes in both synaptic connectivity and BDNF expression under neuropathic pain conditions.
Region-dependent synaptic alterations and BDNF expression induced by SNI are abolished by inhibition or ablation of microglia

We pursued the mechanism by which SNI and resultant elevation of TNF- $\alpha$ regulate BDNF expression and synaptic connectivity oppositely in the spinal dorsal horn and hippocampus. Previous studies showed that activation of microglia impairs LTP in hippocampus (Griffin et al., 2006), but is essential for LTP induction in spinal dorsal horn (Zhong et al., 2010), indicating that microglia have differential effects on synaptic plasticity in the two regions. In the present study, we found that microglia were activated and proliferated in ipsilateral spinal dorsal horn and bilateral hippocampus after SNI in the mice that express GFP in microglial cells (Fig. 6A,B). To determine whether microglial activation is responsible for the opposite cellular and molecular changes induced by SNI, we first inhibited microglia using a tetracycline derivative, minocycline. Injection of minocycline intraperitoneally prevented memory deficits and mechanical allodynia (Fig. 6C) and abolished the upregulation of TNF- $\alpha$ and the opposite changes in BDNF expression (Fig. 6D) in the hippocampus and in spinal dorsal horn produced by SNI in WT mice. 
A
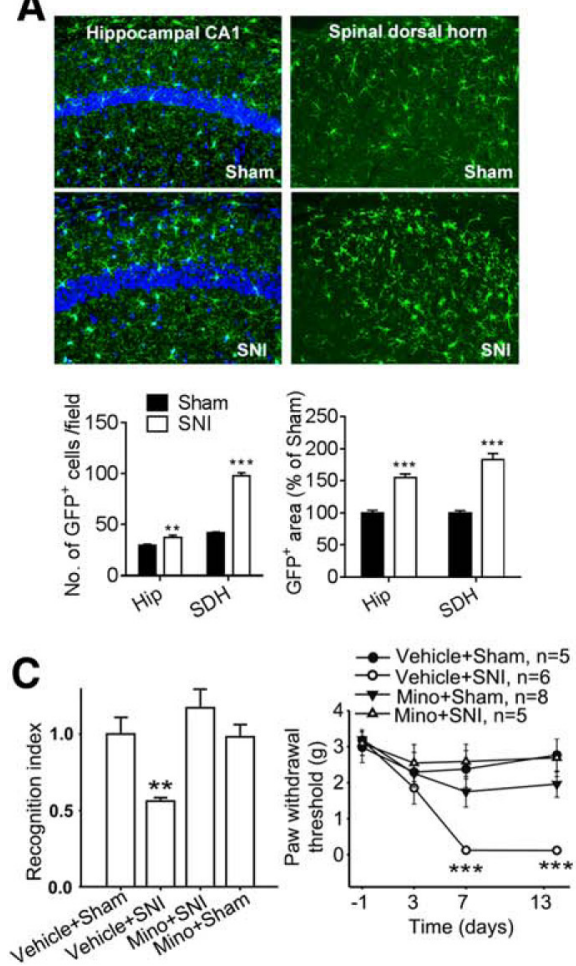

B

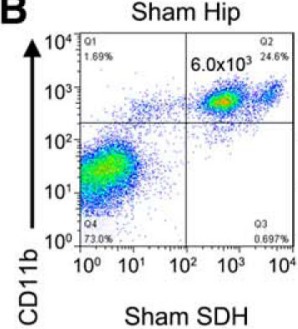

SNI 7d Ipsi-Hip SNI 7d Contr-Hip
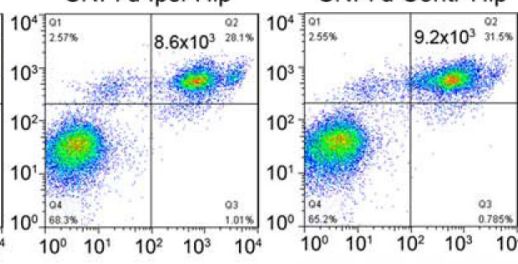

SNI 7d Ipsi-SDH SNI 7d Contr-SDH
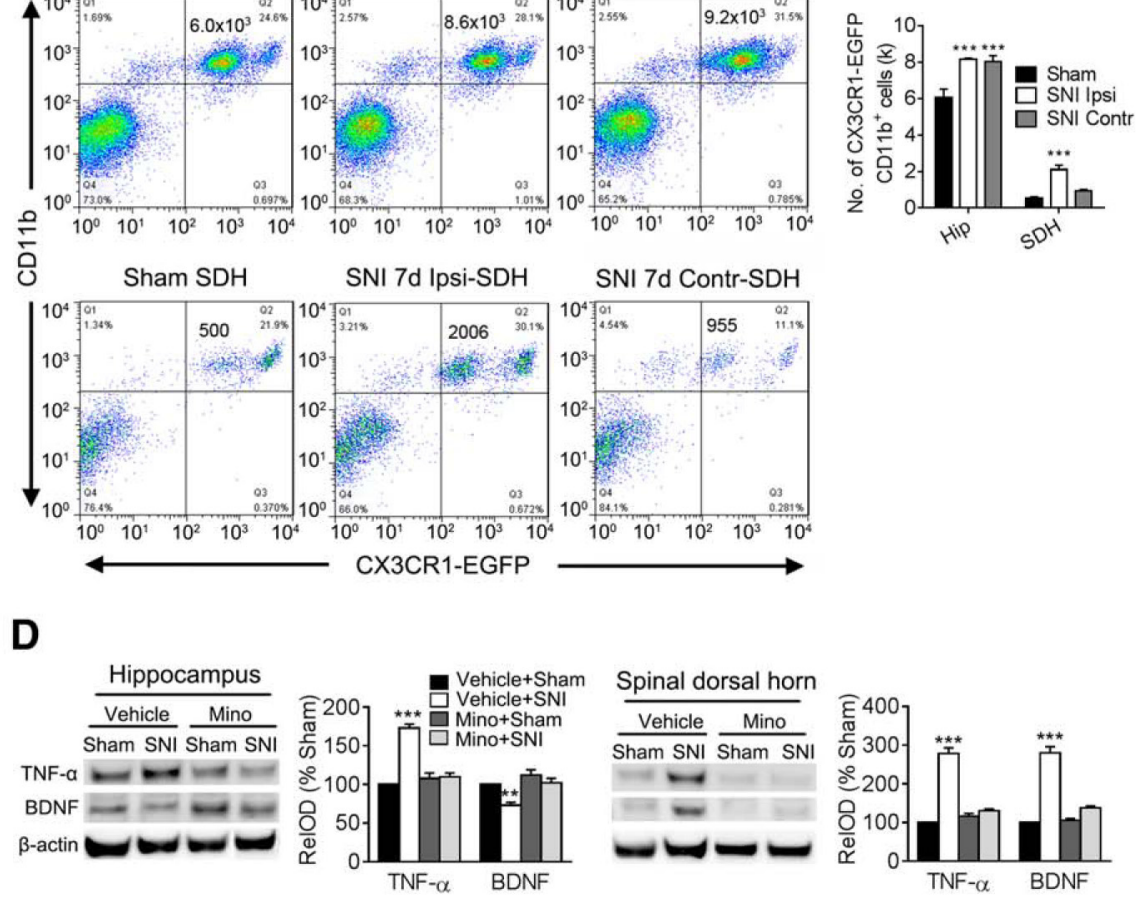

Figure 6. Pharmacological inhibition of microglia prevents the opposite changes in BDNF expression and behavioral abnormalities induced by SNI. $A$, Representative images showing microglial cells (green) and DAPI (blue) in ipsilateral hippocampal CA1 and spinal dorsal horn in CX3CR1-EGFP mice from sham and SNI groups. Pooled results show the number of GFP ${ }^{+}$cells and the percentage of GFP ${ }^{+}$area in the hippocampus (Hip, $n=3, p=0.021$ ) and spinal dorsal horn (SDH, $n=3, p<0.001$ ) of SNI and sham mice 9 d after surgery ( 3 mice for each group). $\boldsymbol{B}$, FACS analysis of microglia in the ipsilateral (ipsi) and contralateral (contr) hippocampus ( $n=4$, sham vs SNI Ipsi, $p<0.001$, sham vs SNI Contr, $p<0.001)$ and spinal dorsal horn $(n=4$, sham vs SNI Ipsi, $p<0.001$, sham vs SNI Contr, $p=0.092$ ) in sham and SNI-7 d mice. Dot plots show the total number of microglial cells expressing CX, CR1-EGFP and CD11b ( 4 mice for each group). C, STM deficit ( $n=8$, Vehicle + Sham vs Vehicle $+\mathrm{SNI}, p=0.013$, Mino + Sham vs Mino $+\mathrm{SNI}, p=0.142$ ) and mechanical allodynia (sample size mentioned in figure, day 7 , Vehicle + Sham vs Vehicle $+\mathrm{SNI}, p<0.001$, Mino + Sham vs Mino + SNl, $p=0.362$; day 13, Vehicle + Sham vs Vehicle $+\mathrm{SNl}, p<0.001$, Mino + Sham vs Mino $+\mathrm{SNl}, p=0.566)$ were prevented by minocycline (30 mg $/ \mathrm{kg}$, i.p., twice a day beginning $1 \mathrm{~d}$ before and continuing for $7 \mathrm{~d}$ after SNI). $\boldsymbol{D}$, Western blots showing the expression of TNF- $\alpha$ and BDNF in hippocampus $(n=5$, TNF- $\alpha$, Vehicle + Sham vs Vehicle + SNI, $p<$ 0.001 , Mino + Sham vs Mino + SNI, $p=0.361 ;$ BDNF, Vehicle + Sham vs Vehicle $+\mathrm{SNI}, p=0.008$, Mino + Sham vs Mino + SNI, $p=0.225)$ and spinal dorsal horn $(n=5$, TNF- $\alpha$, Vehicle + Sham vs Vehicle $+\mathrm{SNI}, p<0.001$, Mino + Sham vs Mino $+\mathrm{SNI}, p=0.566$; BDNF, Vehicle + Sham vs Vehicle $+\mathrm{SNI}, p<0.001$, Mino + Sham vs Mino $+\mathrm{SNI}, p=0.306)$ tissues from the mice that had been used for the above behavioral tests. Values are the mean \pm SEM. ${ }^{*} p<0.05,{ }^{* *} p<0.01,{ }^{* * *} p<0.001$ compared with the values for each of the other three groups. Data for bar graphs in $\boldsymbol{A}$ were analyzed using Student's $t$ test. Data for graphs in $\boldsymbol{C}$ were analyzed using repeated-measures two-way ANOVA. Data for other graphs were analyzed using Student's $t$ test.

To determine whether microglia mediated the SNI-induced CNS region-dependent changes in synaptic connectivity and BDNF expression, as well as behavioral abnormities, we ablated microglia selectively using a mouse line genetically engineered to express the diphtheria toxin receptor in microglia in CNS (Parkhurst et al., 2013; Peng et al., 2016). Exposure to diphtheria toxin resulted in extensive depletion of microglia throughout the CNS, including the hippocampus and spinal cord (M-Abl; Fig. 7A,B). We found that microglial depletion prevented SNI-induced reductions of dendrite complexity, spine density, and the synaptic NMDA/AMPA ratio in hippocampal CA1 pyramidal neurons (Fig. $7 C, D$ ) and the increases in those dendritic features in spinal dorsal horn NK1-PNs (Fig. 7E,F). Finally, the ablation of microglia also prevented the SNI-induced STM deficits and mechanical allodynia (Fig. $7 G$ ) and abolished the increase in TNF- $\alpha$ and the differential changes in BDNF in the hippocampus and spinal dorsal horn (Fig. $7 H$ ). These results suggest a pivotal role for microglial activation in the neurochemical and cytoarchitectural consequences of SNI in the spinal dorsal horn and hippocampus and the associated behavioral manifestations.

\section{Discussion}

We found that dendritic structural complexity and functional synaptic connectivity and BDNF expression were enhanced sig- nificantly in spinal NK1-PNs, but reduced in hippocampal CA1 neurons after SNI. SNI upregulated TNF- $\alpha$ in both hippocampus and spinal dorsal horn and the SNI-induced region-dependent changes in structural synaptic connectivity and BDNF expression were blocked by genetic deletion of TNFR1 in vivo, mimicked by rrTNF- $\alpha$ in cultured hippocampal and spinal slices. SNI also activated microglia in the two regions, whereas the pharmacological inhibition or selective deletion of microglia blocked the SNI-induced changes in synaptic connectivity and BDNF expression and substantially prevented the neuropathic pain and STM deficits. Altogether, our findings suggest that CNS regiondependent changes in synaptic connectivity are responsible for behavioral manifestations of chronic pain, including impaired hippocampus-dependent learning and memory. Microglial activation and TNF- $\alpha$ signaling via TNFR1 are required for the opposite changes in the structural synaptic connectivity in region CAl of the hippocampus and spinal cord dorsal horn.

\section{CNS region-specific effects of SNI on synaptic connectivity} are mediated by microglial activation and TNF- $\alpha$ signaling Previous studies showed that activation of microglia impairs LTP in hippocampus (Griffin et al., 2006), but is essential for LTP induction in spinal dorsal horn (Zhong et al., 2010), indicating that microglial activation also affects synaptic plasticity in a region-dependent manner. Microglia release numerous glio- 


\section{A}

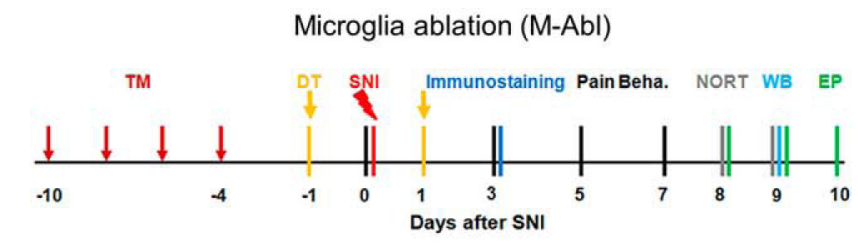

B

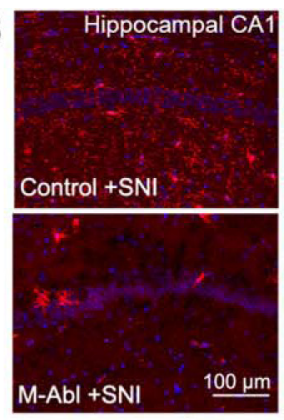

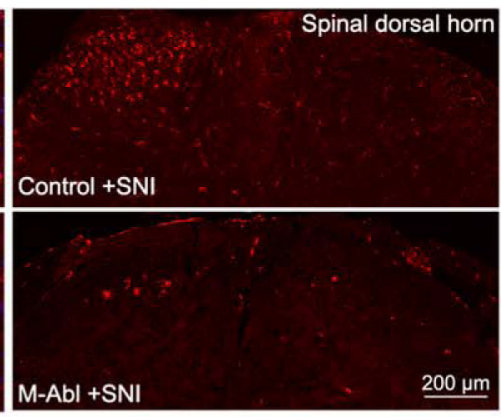

D
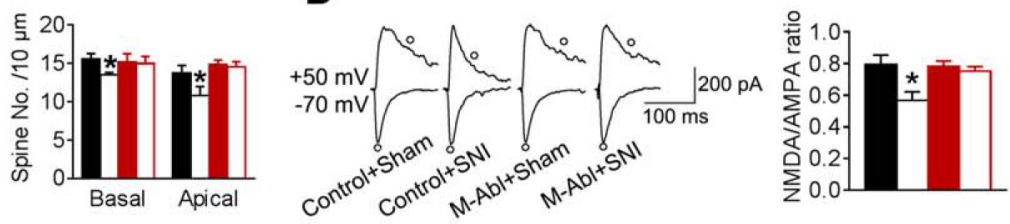

$\mathbf{F}$
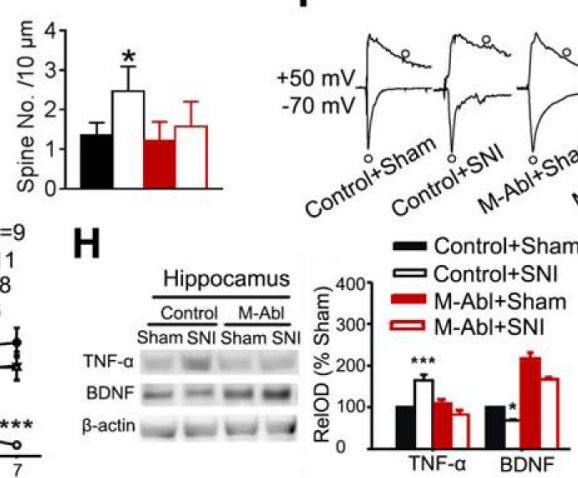

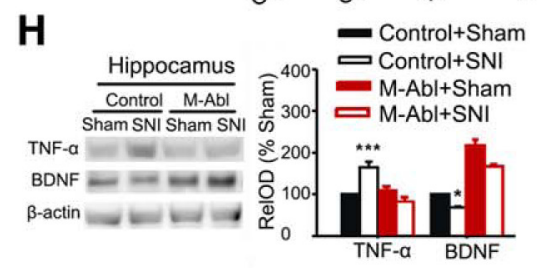

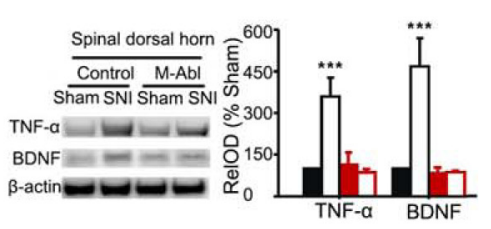

Figure 7. Conditional ablation of microglia prevents the synaptic changes and the behavioral abnormalities resulting from SNI. $A$, The experimental diagram shows the timeline of drug treatments (TM, tamoxifen, DT, diphtheria toxin), immunostaining, Western blots (WB) pain behavioral tests (Pain beha.), novel object recognition test (NORT) and electrophysiology (EP) before and after SNI. B, The photographs show Iba1-positive microglia in the hippocampal CA1 area and spinal dorsal horn of CX3CR1 ${ }^{\mathrm{CreER} /+}$ (Control) and CX3CR1 ${ }^{\mathrm{CreER} /+}$ : R26 ${ }^{\mathrm{DTTR} /+}$ mice (M-Abl) $3 \mathrm{~d}$ after SNI. C, Results of analyses of dendritic length $(n=12$, basal, Control + Sham vs Control + SNI, $p=0.011, \mathrm{M}-\mathrm{Abl}+\mathrm{Sham}$ vs M-Abl + SNI, $p=0.568 ;$ apical, Control + Sham vs Control + SNI, $p=0.035, \mathrm{M}-\mathrm{Abl}+$ Sham vs M-AbI $+\mathrm{SNI}, p=0.399)$, branch number $(n=12$, basal, Control + Sham vs Control $+\mathrm{SNI}, p=0.013, \mathrm{M}-\mathrm{Abl}+\mathrm{Sham}$ vs $\mathrm{M}-\mathrm{Abl}+\mathrm{SNI}, p=0.208$; apical, Control + Sham vs Control $+\mathrm{SNI}, p=0.022, \mathrm{M}-\mathrm{Abl}+$ Sham vs M-Abl $+\mathrm{SNI}, p=0.451$ ), and spine densities of CA1 neurons in sham and SNI groups of control and M-Abl mice ( $n=12$, basal, Control + Sham vs Control + SNI, $p=0.039, \mathrm{M}-\mathrm{Abl}+$ Sham vs M-Abl + SNI, $p=0.602$; apical, Control + Sham vs Control + SNI, $p=0.028$, $\mathrm{M}-\mathrm{Abl}+$ Sham vs $\mathrm{M}-\mathrm{Abl}+\mathrm{SNI}, p=0.375 ; 12$ neurons from 5 mice per group). $\boldsymbol{D}$, The NMDA/AMPA current ratio at CA3-CA1 synapses in SNI group was lower in control mice but not in M-Abl mice, compared with sham groups ( $n=14$, Control + Sham vs Control + SNI, $p=0.022, \mathrm{M}-\mathrm{Abl}+$ Sham vs M-Abl + SNI, $p=0.412)$. $E$, Results of analyses of dendritic length $(n=12$, Control + Sham vs Control $+\mathrm{SNI}, p=0.021, \mathrm{M}-\mathrm{Abl}+$ Sham vs M-AbI $+\mathrm{SNI}, p=0.226)$, branch number $(n=12$, Control + Sham vs Control $+\mathrm{SNI}, p=0.017, \mathrm{M}-\mathrm{Abl}+$ Sham vs M-AbI $+\mathrm{SNI}, p=0.336)$, and spine densities of spinal NK1-PN neurons in sham and SNI groups of control and M-AbI mice $(n=12$, Control + Sham vs Control + SNI, $p=0.014$, $\mathrm{M}-\mathrm{Abl}+$ Sham vs M-Abl + SNI, $p=0.433 ; 12$ neurons from 5 mice per group). $\boldsymbol{F}$, The NMDA/AMPA current ratio in spinal NK1-PNs in different groups $(n=12$, Control + Sham vs Control + SNI, $p=0.031, \mathrm{M}-\mathrm{Abl}+$ Sham vs M-AbI + SNI, $p=0.522) .12$ neurons from 5 mice per group. G, The recognition index for STM $(n=10$, Control + Sham vs Control + SNI, $p=0.026, \mathrm{M}-\mathrm{Abl}+$ Sham vs M-Abl $+\mathrm{SNI}, p=0.559$ ) and mechanical allodynia (sample size mentioned in figure, day 3 , Control + Sham vs Control $+\mathrm{SNI}, p<0.001, \mathrm{M}-\mathrm{Abl}+\mathrm{Sham}$ vs M-Abl + SNI, $p=0.306$; day 5, Control + Sham vs Control + SNI, $p<0.001$, M-Abl + Sham vs M-Abl + SNI, $p=0.528 ;$ day 7, Control + Sham vs Control + SNI, $p<0.001$, $\mathrm{M}-\mathrm{Abl}+$ Sham vs M-Abl + SNI, $p=0.672)$ in sham and SNI groups of control and M-Abl mice. $\boldsymbol{H}$, The expression of TNF- $\alpha$ and BDNF in hippocampal $(n=5$, TNF- $\alpha$, Control + Sham vs Control + SNI, $p<0.001, \mathrm{M}-\mathrm{Abl}+$ Sham vs M-Abl + SNI, $p=0.162 ;$ BDNF, Control + Sham vs Control + SNI, $p=0.035, \mathrm{M}-\mathrm{Abl}+$ Sham vs M-Abl + SNI, $p=0.098)$ and spinal dorsal horn ( $n=5$, TNF- $\alpha$, Control + Sham vs Control + SNI, $p<0.001, \mathrm{M}-\mathrm{Abl}+$ Sham vs M-Abl + SNI, $p=0.377$; BDNF, Control + Sham vs Control + SNI, $p<0.001, \mathrm{M}-\mathrm{Abl}+$ Sham vs $\mathrm{M}-\mathrm{Abl}+\mathrm{SNI}, p=0.568)$ tissues from the mice that had been used for the above behavioral tests. Values are the mean \pm SEM ${ }^{*} p<0.05,{ }^{* *} p<0.01,{ }^{* * *} p<0.001$ compared with the values for each of the other three groups. Data for graphs in $\mathbf{G}$ were analyzed using repeated-measures two-way ANOVA. Data for other graphs were analyzed using Student's $t$ test.

transmitters, including cytokines, neurotrophic factors, and neurotransmitters (Ransohoff and Perry, 2009; Eyo and Wu, 2013), and these chemical substances may create and maintain a microenvironment that modulates the structure and function of the cells. Under neuropathic pain conditions, it is well known that spinal microglia are activated strongly at both the molecular and cellular level, thereby regulating neuronal activities in the spinal dorsal horn (Zhuo et al., 2011; Gu et al., 2016; Jeong et al., 2016). However, the peripheral nerve injury-induced microglia activa- tion in the brain is less conclusive. For example, a previous study showed that ligation of common peroneal nerve fails to activate cortical or hippocampal microglia (Zhang et al., 2008), which is different from the current study. We believe that the different pain models used in the studies may underlie the discrepancy. Indeed, Takeda et al. (2009) reported that the expression of CD11b, a microglial marker, was increased in the hypothalamus and periaqueductal gray in the chronic constriction injury rats. In addition, it has been shown that peripheral 
inflammation induces microglia activation in the hippocampus (Riazi et al., 2008). A recent genome-wide analysis study shows that microglia have distinct brain-region-dependent transcriptional identities (Grabert et al., 2016). Accordingly, the gliotransmitters released by activated microglia in hippocampus and in spinal dorsal horn may be different under neuropathic pain conditions. If this is true, then the opposite changes in synaptic connectivity in the two regions may result from the different microenvironment mediated by microglia. Indeed, our data showing that SNI-induced opposite changes in synaptic connectivity and BDNF expression were prevented by either pharmacological inhibition or genetic ablation of microglia demonstrate directly that the region-dependent changes induced by SNI are mediated by microglial activation.

Similar to peripheral nerve injury and microglial activation, TNF- $\alpha$ overproduction also regulates synaptic plasticity region dependently: induction of LTP in the spinal dorsal horn (Liu et al., 2007; Zhong et al., 2010; Gruber-Schoffnegger et al., 2013) and inhibition of LTP in the hippocampus (Pickering et al., 2005; Griffin et al., 2006; Ren et al., 2011). The present study showed that SNI-induced opposite changes in structural synaptic connectivity in hippocampus and in spinal dorsal horn were abolished by genetic deletion of TNFR 1 and mimicked by $\operatorname{rrTNF}-\alpha$ in slice cultures. The mechanisms underlying the effects of TNF- $\alpha /$ TNFR1 signaling are still unclear. In neuropathic conditions, TNF- $\alpha$ released from neurons and glial cells (Xu et al., 2006) can activate microglia via TNFR1 in vivo (Ishikawa et al., 2013) and in vitro (Neniskyte et al., 2014). Therefore, TNF- $\alpha$-induced CNS region-dependent changes may be at least partially mediated by microglia TNFR1.

\section{BDNF in SNI-induced structural and synaptic plasticity in the hippocampus and spinal dorsal horn}

It is well established that LTP and learning are associated with increases in dendritic spines in hippocampal and cortical neurons (Holtmaat and Svoboda, 2009) and the structural plasticity is believed to underlie long-term memory formation (Bailey and Kandel, 1993). The change in spine number is associated with functional changes in synaptic connectivity and behavioral changes. For example, animal studies have shown that exercise and caloric restriction increase dendritic spine density in hippocampal neurons and improve learning and memory, whereas diabetes and depression reduce spine density and impair learning and memory (Stranahan et al., 2009; Mattson, 2012). Previous findings showed that peripheral nerve injury leads to neuropathic pain (Decosterd and Woolf, 2000) and induces LTP at C-fiber synapses in spinal dorsal horn (Zhang et al., 2004), but inhibits LTP at CA3-CA1 synapses in hippocampus (Ren et al., 2011). We found that the total dendrite length, number of dendrite branch points, and spine densities were reduced in CA1 pyramidal neurons but enhanced in spinal NK1-PNs 7-10 d after SNI. Because most excitatory synapses are located in spines (Sorra and Harris, 2000), the opposite structural synaptic changes may contribute to long-lasting memory deficits and chronic neuropathic pain by decreasing and increasing excitatory synaptic transmission in hippocampus and in spinal dorsal horn, respectively. The reduction of the dendritic complexity in hippocampus may also contribute to the hippocampal atrophy in chronic pain patients (Mutso et al., 2012; Mao et al., 2016).

BDNF is critical for dendritic growth, synapse formation, and functional synaptic plasticity in several CNS regions, including the hippocampus and spinal dorsal horn (Coull et al., 2005; Zhou et al., 2010). We found that BDNF levels were reduced in hip- pocampus but increased in spinal dorsal horn after SNI and that these changes in BDNF were mediated by microglia activation and TNFR1. These findings are consistent with a scenario in which microglia-derived TNF- $\alpha$ regulates BDNF expression differentially in hippocampal CA1 and spinal dorsal horn neurons. Given that BDNF is known to stimulate dendrite growth and synaptogenesis in both CNS regions (Lu et al., 2013), it seems likely that changes in BDNF expression contribute to the differential effects of SNI on dendritic architecture and synaptic connectivity in hippocampal CA1 pyramidal neurons and spinal NK-1 receptor-expressing neurons.

Altogether, our study demonstrates a differential regulation of synaptic plasticity in the hippocampus and spinal cord by a TNF- $\alpha$ - and microglia-dependent mechanism after peripheral nerve injury. These findings suggest that suppression of microglial activation or inhibition of TNFR1 might ameliorate the adverse effects of chronic pain on mood and learning and memory. They may also explain, in part, the fact that exercise is beneficial for chronic pain patients because it reduces pain perception and also exhibits antidepressant and cognition-enhancing effects (Ambrose and Golightly, 2015). Interestingly, exercise increases BDNF expression in the hippocampus, but suppresses BDNF production in the spinal dorsal horn (Mattson, 2012; Almeida et al., 2015). It will be of considerable interest to determine whether there are roles for microglia and TNF- $\alpha$ in these beneficial effects of exercise on chronic pain.

\section{References}

Al Ghamdi KS, Polgár E, Todd AJ (2009) Soma size distinguishes projection neurons from neurokinin 1 receptor-expressing interneurons in lamina I of the rat lumbar spinal dorsal horn. Neuroscience 164:1794-1804. CrossRef Medline

Almeida C, DeMaman A, Kusuda R, Cadetti F, Ravanelli MI, Queiroz AL, Sousa TA, Zanon S, Silveira LR, Lucas G (2015) Exercise therapy normalizes BDNF upregulation and glial hyperactivity in a mouse model of neuropathic pain. Pain 156:504-513. CrossRef Medline

Ambrose KR, Golightly YM (2015) Physical exercise as non-pharmacological treatment of chronic pain: why and when. Best Pract Res Clin Rheumatol 29:120-130. CrossRef Medline

Awh E, Vogel EK, Oh SH (2006) Interactions between attention and working memory. Neuroscience 139:201-208. CrossRef Medline

Bailey CH, Kandel ER (1993) Structural changes accompanying memory storage. Annu Rev Physiol 55:397-426. CrossRef Medline

Coull JA, Beggs S, Boudreau D, Boivin D, Tsuda M, Inoue K, Gravel C, Salter MW, De Koninck Y (2005) BDNF from microglia causes the shift in neuronal anion gradient underlying neuropathic pain. Nature 438:10171021. CrossRef Medline

Decosterd I, Woolf CJ (2000) Spared nerve injury: an animal model of persistent peripheral neuropathic pain. Pain 87:149-158. CrossRef Medline

Dick BD, Rashiq S (2007) Disruption of attention and working memory traces in individuals with chronic pain. Anesth Analg 104:1223-1229. CrossRef Medline

Eccleston C (1995) Chronic pain and distraction: An experimental investigation into the role of sustained and shifting attention in the processing of chronic persistent pain. Behaviour Research and Therapy 33:391-405. CrossRef Medline

Eyo UB, Wu LJ (2013) Bidirectional microglia-neuron communication in the healthy brain. Neural Plast 2013:456857. CrossRef Medline

Grabert K, Michoel T, Karavolos MH, Clohisey S, Baillie JK, Stevens MP, Freeman TC, Summers KM, McColl BW (2016) Microglial brain region-dependent diversity and selective regional sensitivities to aging. Nat Neurosci 2016;19:504-516. CrossRef Medline

Griffin R, Nally R, Nolan Y, McCartney Y, Linden J, Lynch MA (2006) The age-related attenuation in long-term potentiation is associated with microglial activation. J Neurochem 99:1263-1272. CrossRef Medline

Groth R, Aanonsen L (2002) Spinal brain-derived neurotrophic factor (BDNF) produces hyperalgesia in normal mice while antisense directed against either BDNF or trkB, prevent inflammation-induced hyperalgesia. Pain 100:171-181. CrossRef Medline 
Gruber-Schoffnegger D, Drdla-Schutting R, Hönigsperger C, Wunderbaldinger G, Gassner M, Sandkühler J (2013) Induction of thermal hyperalgesia and synaptic long-term potentiation in the spinal cord lamina I by TNF-alpha and IL-1beta is mediated by glial cells. J Neurosci 33: 6540-6551. CrossRef Medline

Gu N, Peng J, Murugan M, Wang X, Eyo UB, Sun D, Ren Y, DiCicco-Bloom E, Young W, Dong H, Wu LJ (2016) Spinal microgliosis due to resident microglial proliferation is required for pain hypersensitivity after peripheral nerve injury. Cell Rep 16:605-614. CrossRef Medline

Hart RP, Martelli MF, Zasler ND (2000) Chronic pain and neuropsychological functioning. Neuropsychol Rev 10:131-149. CrossRef Medline

Holtmaat A, Svoboda K (2009) Experience-dependent structural synaptic plasticity in the mammalian brain. Nat Rev Neurosci 10:647-658. CrossRef Medline

Ishikawa T, Miyagi M, Kamoda H, Orita S, Eguchi Y, Arai G, Suzuki M, Sakuma Y, Oikawa Y, Inoue G, Aoki Y, Toyone T, Takahashi K, Ohtori S (2013) Differences between tumor necrosis factor-alpha receptors types 1 and 2 in the modulation of spinal glial cell activation and mechanical allodynia in a rat sciatic nerve injury model. Spine 38:11-16. CrossRef Medline

Jeong H, Na YJ, Lee K, Kim YH, Lee Y, Kang M, Jiang BC, Yeom YI, Wu LJ, Gao YJ, Kim J, Oh SB (2016) High-resolution transcriptome analysis reveals neuropathic pain gene-expression signatures in spinal microglia after nerve injury. Pain 157:964-976. CrossRef Medline

Ji RR, Suter MR (2007) p38 MAPK, microglial signaling, and neuropathic pain. Mol Pain 3:33. CrossRef Medline

Lau CG, Zukin RS (2007) NMDA receptor trafficking in synaptic plasticity and neuropsychiatric disorders. Nat Rev Neurosci 8:413-426. Medline

Liu YL, Zhou LJ, Hu NW, Xu JT, Wu CY, Zhang T, Li YY, Liu XG (2007) Tumor necrosis factor-alpha induces long-term potentiation of C-fiber evoked field potentials in spinal dorsal horn in rats with nerve injury: the role of NF-kappa B, JNK and p38 MAPK. Neuropharmacology 52:708715. CrossRef Medline

Lu B, Nagappan G, Guan X, Nathan PJ, Wren P (2013) BDNF-based synaptic repair as a disease-modifying strategy for neurodegenerative diseases. Nat Rev Neurosci 14:401-416. CrossRef Medline

Mantyh PW, Rogers SD, Honore P, Allen BJ, Ghilardi JR, Li J, Daughters RS, Lappi DA, Wiley RG, Simone DA (1997) Inhibition of hyperalgesia by ablation of lamina I spinal neurons expressing the substance P receptor. Science 278:275-279. CrossRef Medline

Mao CP, Bai ZL, Zhang XN, Zhang QJ, Zhang L (2016) Abnormal subcortical brain morphology in patients with knee osteoarthritis: a crosssectional study. Front Aging Neurosci 8:3. CrossRef Medline

Mattson MP (2012) Energy intake and exercise as determinants of brain health and vulnerability to injury and disease. Cell Metab 16:706-722. CrossRef Medline

Mutso AA, Radzicki D, Baliki MN, Huang L, Banisadr G, Centeno MV, Radulovic J, Martina M, Miller RJ, Apkarian AV (2012) Abnormalities in hippocampal functioning with persistent pain. J Neurosci 32:5747-5756. CrossRef Medline

Nakatsuka T, Ataka T, Kumamoto E, Tamaki T, Yoshimura M (2000) Alteration in synaptic inputs through C-afferent fibers to substantia gelatinosa neurons of the rat spinal dorsal horn during postnatal development. Neuroscience 99:549-556. CrossRef Medline

Neniskyte U, Vilalta A, Brown GC (2014) Tumour necrosis factor alphainduced neuronal loss is mediated by microglial phagocytosis. FEBS Lett 588:2952-2956. CrossRef Medline

Pagliardini S, Adachi T, Ren J, Funk GD, Greer JJ (2005) Fluorescent tagging of rhythmically active respiratory neurons within the pre-Botzinger complex of rat medullary slice preparations. J Neurosci 25:2591-2596. CrossRef Medline

Park H, Poo MM (2013) Neurotrophin regulation of neural circuit development and function. Nat Rev Neurosci 14:7-23. CrossRef Medline

Parkhurst CN, Yang G, Ninan I, Savas JN, Yates JR 3rd, Lafaille JJ, Hempstead BL, Littman DR, Gan WB (2013) Microglia promote learning- dependent synapse formation through brain-derived neurotrophic factor. Cell 155:1596-1609. CrossRef Medline

Peng J, Gu N, Zhou L, B Euo U, Murugan M, Gan WB, Wu LJ (2016) Microglia and monocytes synergistically promote the transition from acute to chronic pain after nerve injury. Nat Commun 7:12029. CrossRef Medline

Pickering M, Cumiskey D, O'Connor JJ (2005) Actions of TNF-alpha on glutamatergic synaptic transmission in the central nervous system. Exp Physiol 90:663-670. CrossRef Medline

Ransohoff RM, Perry VH (2009) Microglial physiology: unique stimuli, specialized responses. Annu Rev Immunol 27:119-145. CrossRef Medline

Ren WJ, Liu Y, Zhou LJ, Li W, Zhong Y, Pang RP, Xin WJ, Wei XH, Wang J, Zhu HQ, Wu CY, Qin ZH, Liu G, Liu XG (2011) Peripheral nerve injury leads to working memory deficits and dysfunction of the hippocampus by upregulation of TNF-alpha in rodents. Neuropsychopharmacology 36 : 979-992. CrossRef Medline

Riazi K, Galic MA, Kuzmiski JB, Ho W, Sharkey KA, Pittman QJ (2008) Microglial activation and TNFalpha production mediate altered CNS excitability following peripheral inflammation. Proc Natl Acad Sci U S A 105:17151-17156. CrossRef Medline

Rowan MJ, Klyubin I, Wang Q, Hu NW, Anwyl R (2007) Synaptic memory mechanisms: Alzheimer's disease amyloid beta-peptide-induced dysfunction. Biochem Soc Trans 35:1219-1223. CrossRef Medline

Sorra KE, Harris KM (2000) Overview on the structure, composition, function, development, and plasticity of hippocampal dendritic spines. Hippocampus 10:501-511. Medline

Stranahan AM, Lee K, Martin B, Maudsley S, Golden E, Cutler RG, Mattson MP (2009) Voluntary exercise and caloric restriction enhance hippocampal dendritic spine density and BDNF levels in diabetic mice. Hippocampus 19:951-961. CrossRef Medline

Takeda K, Muramatsu M, Chikuma T, Kato T (2009) Effect of memantine on the levels of neuropeptides and microglial cells in the brain regions of rats with neuropathic pain. J Mol Neurosci 39:380-390. CrossRef Medline

Wu Y, Na X, Zang Y, Cui Y, Xin W, Pang R, Zhou L, Wei X, Li Y, Liu X (2014) Upregulation of tumor necrosis factor-alpha in nucleus accumbens attenuates morphine-induced rewarding in a neuropathic pain model. Biochem Biophys Res Commun 449:502-507. CrossRef Medline

Xu JT, Xin WJ, Zang Y, Wu CY, Liu XG (2006) The role of tumor necrosis factor-alpha in the neuropathic pain induced by Lumbar 5 ventral root transection in rat. Pain 123:306-321. CrossRef Medline

Yu XH, Ribeiro-da-Silva A, De Koninck Y (2005) Morphology and neurokinin 1 receptor expression of spinothalamic lamina I neurons in the rat spinal cord. J Comp Neurol 491:56-68. CrossRef Medline

Yu XH, Zhang ET, Craig AD, Shigemoto R, Ribeiro-da-Silva A, De Koninck Y (1999) NK-1 receptor immunoreactivity in distinct morphological types of lamina I neurons of the primate spinal cord. J Neurosci 19:3545-3555. Medline

Zhang F, Vadakkan KI, Kim SS, Wu LJ, Shang Y, Zhuo M (2008) Selective activation of microglia in spinal cord but not higher cortical regions following nerve injury in adult mouse. Mol Pain 4:15. CrossRef Medline

Zhang HM, Zhou LJ, Hu XD, Hu NW, Zhang T, Liu XG (2004) Acute nerve injury induces long-term potentiation of C-fiber evoked field potentials in spinal dorsal horn of intact rat. Sheng Li Xue Bao 56:591-596. Medline

Zhong Y, Zhou LJ, Ren WJ, Xin WJ, Li YY, Zhang T, Liu XG (2010) The direction of synaptic plasticity mediated by C-fibers in spinal dorsal horn is decided by Src-family kinases in microglia: the role of tumor necrosis factor-alpha. Brain Behav Immun 24:874-880. CrossRef Medline

Zhou LJ, Ren WJ, Zhong Y, Yang T, Wei XH, Xin WJ, Liu CC, Zhou LH, Li YY, Liu XG (2010) Limited BDNF contributes to the failure of injury to skin afferents to produce a neuropathic pain condition. Pain 148: 148-157. CrossRef Medline

Zhuo M, Wu G, Wu LJ (2011) Neuronal and microglial mechanisms of neuropathic pain. Mol Brain 4:31. CrossRef Medline 